Regina Céla Teixerra Gomes ${ }^{1}$

Patrícia Bedesco de Olivelra ${ }^{2}$

Alexandre Gullierme Zabeu Rossi ${ }^{3}$

Maria CÂNDIDA PINHERO Baracat ${ }^{4}$

Ricardo SANTOS SimÕes ${ }^{5}$

EDMUUND ChADA BARACAT ${ }^{6}$

JOSÉ MARIA SOARES JUNIOR ${ }^{7}$

\title{
Efeitos da hiperprolactinemia sobre o útero de camundongos no proestro
}

\author{
Hyperprolactinemia effects on the female mice uterus during proestrous
}

Artigo original

\begin{abstract}
Palavras-chave
Hiperprolactinemia/induzido quimicamente

Metoclopramida/administração \& dosagem Camundongos

Endométrio/efeitos de drogas Endométrio/patologia

Hormônios

Proestro

Morfologia

Keywords

Hyperprolactinemia/chemically induced Metoclopramide/administration \& dosage

Mice

Endometrium/drug effects Endometrium/pathology

Hormones

Proestrus

Morphology
\end{abstract}

José Maria Soares Júnio Departamento de Ginecologia da Universidade Federal de São Paulo Rua Napoleão de Barros, $740,7^{\circ}$ andar - Vila Clementino CEP 04043007 - São Paulo (SP), Brasi E-mail: jsoares415@hotmail.com

Recebido

$29 / 6 / 09$

Aceito com modificacões

24/7/09

\section{Resumo}

OBJETIVO: avaliar o efeito da hiperprolactinemia induzida pela metoclopramida sobre o endométrio e miométrio de camundongos fêmeas na fase de proestro. MÉTODOS: 24 camundongos fêmeas foram divididas aleatoriamente em dois grupos: GCtr/controle e GExp/tratadas com metoclopramida (6,7 $\mu \mathrm{g} / \mathrm{g}$ por dia). Após 50 dias, os animais foram sacrificados na fase de proestro, e o sangue foi coletado para determinação dos níveis de estradiol, progesterona e prolactina. Os cornos uterinos foram removidos e fixados em formol a 10\%; foram, então, processados para inclusão em parafina. Cortes de $4 \mu \mathrm{m}$ foram corados pela hematoxilina-eosina $(H / E)$. Na análise morfológica, foi utilizado microscópio de luz, da marca Carl Zeiss, com objetivas variando de 4 a 400 X, para caracterização de cada corte histológico. Na análise morfométrica, foi avaliada a espessura do epitélio superficial, da lâmina própria e do miométrio, com auxílio de um analisador de imagem (AxionVision, Carl Zeiss) acoplado ao microscópio de luz (Carl Zeiss). A análise estatística foi realizada pela ANOVA seguida pelo teste Wilcoxon. $\bigcirc$ valor de $p$ foi considerado significante quando < 0,05. RESULTADOS: os achados mostraram aumento dos níveis séricos de prolactina $(295,6 \pm 38,0 \mathrm{ng} /$ $\mathrm{mL}$ ) e redução significante dos de progesterona $(11,3 \pm 0,9 \mathrm{ng} / \mathrm{mL})$ no GExp em comparação ao GCtr $(45,5 \pm 5,2$ $\mathrm{ng} / \mathrm{mL}$ e 18,2 $\pm 1,6 \mathrm{ng} / \mathrm{mL}$, respectivamente) ( $\mathrm{p}<0,001$ ). Com relação aos níveis séricos de estradiol, não foram

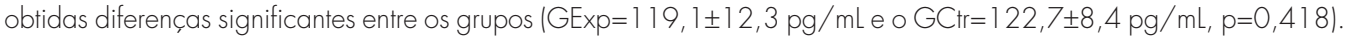
○ estudo morfológico mostrou que o útero do GExp apresentou endométrio com epitélio superficial e lâmina própria mais desenvolvida quando comparado ao GCtr, o mesmo ocorrendo no miométrio. Os valores morfométricos das espessuras do epitélio luminal $(8,0 \pm 1,1 \mu \mathrm{m})$ e do endométrio $\left(116,2 \pm 21,1 \times 10^{2} \mu \mathrm{m}\right)$ do GCtr foram inferiores ao $\operatorname{GExp}\left(10,2 \pm 0,8 \mu \mathrm{m}\right.$ e 163,2 $\pm 23,3 \times 10^{2} \mu \mathrm{m}$ com p<0,05) respectivamente. Já os dados obtidos no miométrio não mostraram diferenças significantes entre si (GCtr $=152,2 \pm 25,2 \times 10^{2} \mu \mathrm{m}$ e GExp $=140,8 \pm 18,0 \times 10^{2} \mu \mathrm{m}$ ). CONCLUSÕES: os dados mostraram que a hiperprolactinemia induzida pela metoclopramida determina proliferação endometrial e interfere na função ovariana, principalmente na produção de progesterona.

\section{Abstract}

PURPOSE: to evaluate the effect of hyperprolactinemia induced by metoclopramide on the endometrium and myometrium of female mice in the proestrus phase. METHODS: 24 female mice were randomly divided in two groups: CtrG/control and ExpG/treated with metoclopramide $(6.7 \mathrm{mg} / \mathrm{g}$ daily). After 50 days, the animals were sacrificed in the proestrus phase, and the blood was collected to determine the levels of estradiol, progesterone and prolactin. The uterine horns were removed, fixed in 10\% formaldehyde and processed before being included in paraffin. Slices of $4 \mu \mathrm{m}$ were stained by hematoxylin and eosin $(\mathrm{H} / \mathrm{E})$. In the morphological analysis, a Carl Zeiss light microscope, with objectives varying from 4 to $400 \mathrm{X}$ was used for each histological slice characterization. In the morphometrical analysis, the superficial epithelium, the lamina propria and the myometrium thickness were evaluated, with the help of an image analyzer (AxionVision - Carl Zeiss) attached to the light microscope (Carl Zeiss). The statistical analysis was done by ANOVA, followed by the Wilcoxon test. P-value was considered as significant, when $<0.05$. RESULTS: our findings
Disciplina de Ginecologia Endócrina da Universidade Federal de São Paulo - UNIFESP - São Paulo (SP), Brasil.

' Pós-graduanda (Doutorado) do Departamento de Ginecologia da Universidade Federal de São Paulo - UNIFESP - São Paulo (SP), Brasil.

${ }^{2}$ Acadêmica, Bolsista do Programa Institucional de Bolsas de Iniciação Científica (PIB|C) do Conselho Nacional de Desenvolvimento Científico e Tecnológico (CNPq) do Curso Médico da Universidade Federal de São Paulo - UNIFESP - São Paulo (SP), Brasil.

${ }^{3}$ Médico Voluntário do Departamento de Ginecologia da Universidade Federal de São Paulo - UNIFESP - São Paulo (SP), Brasil.

${ }^{4}$ Acadêmica, Bolsista do Programa Institucional de Bolsas de Iniciação Científica (PIBIC) do Conselho Nacional de Desenvolvimento Científico e Tecnológico (CNPa) do Curso Médico da Universidade de Santo Amaro - UNISA - São Paulo (SP), Brasil.

5 Pós-Graduando (Mestrado) do Departamento de Obstetrícia e Ginecologia da Faculdade de Medicina da Universidade de São Paulo - USP - São Paulo (SP), Brasil.

- Professor Titular de Obstetrícia do Departamento de Obstetrícia e Ginecologia da Faculdade de Medicina da Universidade de São Paulo - USP - São Paulo (SP), Brasil.

7 Professor Livre-docente do Departamento de Ginecologia da Universidade Federal de São Paulo - UNIFESP - São Paulo (SP), Brasil. 
have shown an increase in the seric levels of prolactin $(295.6 \pm 38.0 \mathrm{ng} / \mathrm{mL})$ and significant decrease in the progesterone levels $(11.3 \pm 0.9 \mathrm{ng} / \mathrm{mL})$ in the ExpG, as compared to the $\operatorname{CrG}(45.5 \pm 5.2 \mathrm{ng} / \mathrm{mL}$ and $18.2 \pm 1.6 \mathrm{ng} / \mathrm{mL}$, respectively; $\mathrm{p}<0.001)$. Concerning the seric level of estradiol, significant differences between the groups were not obtained (ExpG=119.1 $\pm 12.3 \mathrm{pg} / \mathrm{mL}$ and $\mathrm{CtrG}=122.7 \pm 8.4 \mathrm{pg} / \mathrm{mL} ; \mathrm{p}=0.418$ ). The morphological study has shown that the uterus from the ExpG presented the endometrium with more developed superficial epithelium and lamina propria, as compared to the Ctr $G$, the same happening with the myometrium. The thickness morphometrical values of the luminal epithelium $(8.0 \pm 1.1 \mu \mathrm{m})$ and endometrium (1 $16.2 \pm 21.1 \times 10^{2}$ $\mu \mathrm{m})$ from the CtrG were lower than the ones from the ExpG (10.2 $\pm 0.8 \mu \mathrm{m}$ and $163.2 \pm 23.3 \times 10^{2} \mu \mathrm{m}$, respectively) with $\mathrm{p}<0.05$. Nevertheless, data obtained in the myometrium have not shown significant differences between the groups ( $\mathrm{CtrG}=152.2 \pm 25.2 \times 10^{2} \mu \mathrm{m}$ and ExpG=140.8 $\left.\pm 18.0 \times 10^{2} \mu \mathrm{m}\right)$. CONCLUSIONS: data have shown that hyperprolactinemia induced by metoclopramide determines endometrial proliferation and interferes with the ovarian function, mainly in the progesterone production.

\section{Introdução}

A hiperprolactinemia representa a síndrome mais comum de hipersecreção hipofisária, tanto em homens como em mulheres ${ }^{1}$. É observada em 20 a $30 \%$ das pacientes jovens com amenorreia secundária ${ }^{2}$. Assim, o estudo das repercussões da hiperprolactinemia sobre o trato genital assume grande importância clínica.

A prolactina (PRL) tem a particularidade de operar sem um retrocontrole direto, estando sob controle hipotalâmico sob complexo sistema regulador duplo, o qual envolve um controle tanto inibitório como estimulador, por via neuroendócrina, autócrina ou parácrina ${ }^{3}$. Entre os fatores inibidores, a dopamina (DOPA) e o ácido $\gamma$-aminobutírico (GABA) são os mais importantes ${ }^{3}$. A DOPA é secretada e liberada pelos neurônios dopaminérgicos tuberoinfundibulares na eminência média que ativa receptores DOPA D2 na pituitária onde inibe a produção de $\mathrm{PRL}^{4}$. A biossíntese de DOPA ocorre nos terminais axônicos, os quais estão em contato com os capilares portais e liberam-na na circulação porta-hipofisária. Ademais, a capacidade da DOPA em inibir a liberação de PRL foi demonstrada tanto in vitro quanto in vivo ${ }^{4}$. É conhecido o fato de que a atividade inibitória da DOPA é muito maior que a do GABA ${ }^{5}$.

Enquanto o controle hipotalâmico da secreção de PRL se faz por um mecanismo inibitório tônico, a ação dos fatores liberadores seria necessária para as atividades secretoras agudas. Sob certas condições, a secreção de PRL aumentada não se acompanha por diminuição mensurável nos níveis de DOPA no sangue portal ${ }^{5}$. Além disso, a liberação aguda de PRL pode ocorrer mesmo sob inibição máxima da DOPA ${ }^{4}$. Evidências experimentais em várias espécies, incluindo a humana, sugerem que o hormônio liberador de tireotrofina, a serotonina, os peptídeos opioides, a histamina, a ocitocina, a angiotensina, entre outros, estariam envolvidos no controle da secreção de PRL. Assim, a neurorregulação da secreção de PRL seria multifatorial ${ }^{3,4}$. Agentes antidopaminérgicos também teriam a capacidade de elevar a $\mathrm{PRL}^{6-8}$.

A metoclopramida, substância derivada da procainamida, é comumente utilizada para regular a motilidade da porção superior do aparelho gastrintestinal e também como antiemética ${ }^{7,8}$. É um bloqueador específico do receptor de DOPA. Ao neutralizar o efeito inibitório da DOPA, aumenta a secreção de PRL pelos lactotrofos. Assim, a responsividade da PRL à metoclopramida pode diferir de acordo com as concentrações de DOPA na circulação porta-hipofisária ou com a sensibilidade dos lactotrofos à DOPA ${ }^{9}$. Além disso, pode atuar na hipófise, degranulando as células lactotróficas e aumentando a síntese de $\mathrm{PRL}^{10}$.

$\mathrm{Na}$ área experimental, a metoclopramida tem sido bastante utilizada em animais, com o propósito de estudar efeitos deste fármaco nos níveis séricos de PRL, bem como as repercussões deste estado hormonal no organismo ${ }^{6,7,11,12}$. O controle da secreção de PRL em camundongos fêmeas ocorre de maneira muito semelhante à da espécie humana, com os mesmos fatores inibidores e liberadores. A determinação dos níveis séricos de PRL é feita quase que exclusivamente por radioimunoensaio homólogo, sendo os valores normais em camundongos fêmeas adultas de 7 a $90 \mathrm{ng} / \mathrm{mL}$ ou de 6 a $12 \mu \mathrm{g} / \mathrm{mg}^{8,9}$.

Experimentos realizados em ratas adultas levaram à conclusão de que a hiperprolactinemia crônica poderia aumentar o tônus dopaminérgico no hipotálamo médio basal (HMB), o que inibiria a secreção de $\mathrm{GnRH}$ e a liberação de $\mathrm{LH}$ pela hipófise ${ }^{13}$. Estes fatos estariam associados aos distúrbios da atividade cíclica hipotálamo-hipofíseoovariana, que foram comprovados em experimentos no nosso laboratório ${ }^{6-9}$.

Em trabalhos anteriores, foi observado que camundongos fêmeas submetidas à hiperprolactinemia experimental tinham maior número de dias na fase de diestro ${ }^{7}$, desde que continuassem apresentando ciclos estrais regulares. A histologia endometrial desses animais apresentou sinais de proliferação do endométrio durante a fase de diestro. Além disso, a hiperprolactinemia induzida pela metoclopramida determina diminuição da produção de progesterona e do número de pinopódios, no endométrio, em camundongos fêmeas adultas, pela microscopia eletrônica de varredura ${ }^{6}$. Foi verificada também a redução do número de implantações embrionárias nesses animais ${ }^{6}$. Contudo, alguns autores não concordam sobre o fato de que a diminuição do número de pinopódios seria suficiente para explicar a redução das taxas de implantação, pois há 
outros sítios no endométrio onde o embrião poderia se ligar para aderir ao endométrio. Assim, é possível que a análise histomorfológica do endométrio e do miométrio na fase de proestro (momento em que ocorre a interação materno-fetal) fornecesse informações sobre as alterações genitais que poderiam influir na redução da fertilidade dos animais tratados com metoclopramida.

\section{Métodos}

O estudo foi realizado no Centro de Desenvolvimento de Modelos Experimentais (CEDEME) e aprovado pelo Comitê de Ética em Pesquisa da Escola Paulista de Medicina da Universidade Federal de São Paulo (UNIFESP/EPM), $n^{\circ} 1205 / 03$. Foram utilizados camundongos fêmeas (Mus musculus), adultas, albinas, com cem dias e virgens. Para tanto, foram mantidos em número de dez por gaiolas, com água e alimentação ad libitum.

Vinte e quatro camundongos fêmeas foram divididos aleatoriamente em dois grupos: GCtr $(n=12)$, tratados com veículo (solução salina $0,9 \%$ ), por via subcutânea; $\operatorname{GExp}(\mathrm{n}=12)$, tratados com metoclopramida $(6,7 \mu \mathrm{g} / \mathrm{g}$ por dia) em solução salina, por via subcutânea ${ }^{7,11}$.

Todos os animais foram tratados durante 50 dias consecutivos, sempre às $10 \mathrm{~h}$. Após a administração do fármaco ou da solução fisiológica, foi feita, durante 15 dias, a coleta de material para colpocitologia, sendo as lâminas coradas pelo Harris-Shorr. No $50^{\circ}$ dia, após uma hora da administração das soluções, os animais que se encontravam na fase de proestro foram sacrificados por decapitação; os animais que não estavam nesta fase continuaram sob tratamento e só foram sacrificados assim que atingiram a referida fase.

Imediatamente após a decapitação dos animais, foi coletado sangue para dosagem de hormônios (estrogênio, progesterona e PRL), que foi imediatamente congelado. A seguir, as porções médias dos cornos uterinos foram retiradas, para processamento histológico em microscopia de luz. Para tanto, os cornos uterinos foram imersos em solução de formol a $10 \%$, em tampão fosfato, por um período de 12 horas. Na sequência, os cornos uterinos foram desidratados, diafanizados e incluídos em parafina. Cortes de $4 \mu \mathrm{m}$ foram corados pela hematoxilina-eosina (H/E). $\mathrm{Na}$ análise morfológica, foi utilizado microscópio de luz, da marca Carl Zeiss, com objetivas que variavam de 4 a $400 \mathrm{X}$ na caracterização de cada corte histológico.

A avaliação morfométrica foi realizada por captura de imagens do endométrio com microscópio de luz (Axiolab Standard 2.0, Carl Zeiss) usando aumento final de $100 \mathrm{X}$ para determinar a espessura do endométrio (distância entre a borda superficial do epitélio luminal e a porção mais interna do miométrio) e do miométrio (as duas camadas musculares); o aumento de $400 \mathrm{X}$ foi utilizado para determinar a espessura do epitélio superficial (distância entre a borda apical das células que revestem o lúmen uterino e sua lâmina basal). Para tanto, o microscópio de luz foi acoplado à videocâmara de alta resolução (AxionCam, Carl Zeiss), sendo as imagens capturadas e analisadas em programa AxionVision Rel 4.6 (Carl Zeiss). Para tanto, são utilizados quatro campos representativos de cada lâmina. Para cada animal, foram preparadas duas lâminas e os cornos uterinos foram divididos em quatro quadrantes, de tal maneira que foram obtidas oito medições para cada variável estudada em cada animal do estudo (Figuras 1A e B).

Foram dosados os níveis de $17 \beta$-estradiol (E2), progesterona (P4) e PRL no soro congelado, por meio do método de radioimunoensaio (RIA) com duplo
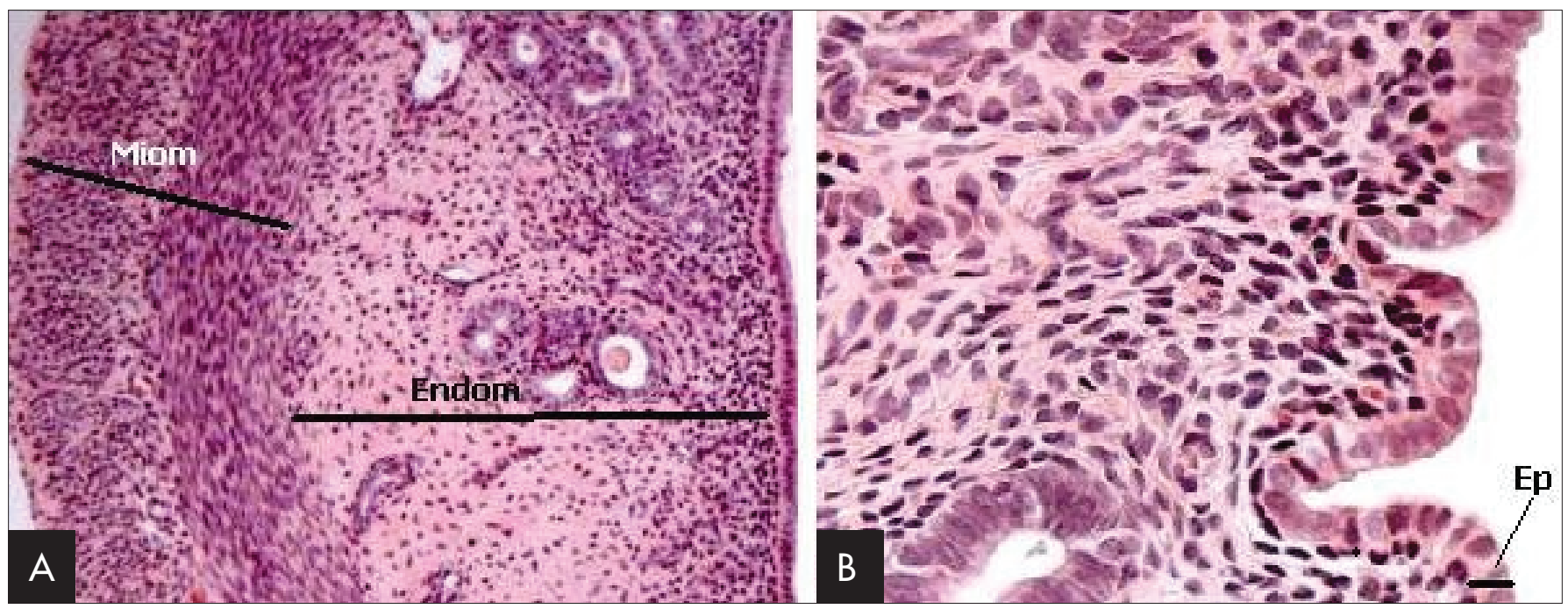

Figura 1 - Fotomicrografias mostrando cortes transversais do útero de camundongo fêmea. Notar, em A, como foram tomadas as medições do miométrio (Miom) e do endométrio (Endom) e, em B, como foi medido o epitélio superficial (Ep). Coloração H/E A=100 X e B=400 X. 
anticorpo (ICN Biomedicals Inc, Costa Mera, CA, USA). Estas dosagens foram feitas no Laboratório Central do Hospital São Paulo da UNIFESP. Após a extração do soro, o material foi incubado com anticorpo marcado com iodo radioativo $\left({ }^{125} \mathrm{I}\right)$ a $4{ }^{\circ} \mathrm{C}$, por 16 a 18 horas. As dosagens foram feitas em duplicata. A porcentagem máxima de reatividade cruzada deste kit era inferior a 0,01\% (especificidade).

Os valores séricos de PRL, estradiol e progesterona, assim como os valores obtidos na morfometria (espessura do epitélio superficial, endométrio e miométrio) são apresentados como médias \pm EPM. A análise estatística foi realizada pela ANOVA seguida pelo teste não paramétrico Wilcoxon. Valores de $\mathrm{p}<0,05$ foram considerados como significativos.

\section{Resultados}

Confirmando a eficácia do tratamento imposto pela metaclopramida, os níveis de PRL mostraram-se mais elevados no grupo tratado com a droga (GCtr $=45,5 \pm 5,2$ $\mathrm{ng} / \mathrm{mL}$ e GExp=295,6士38,0 ng/mL; p<0,001). Os níveis séricos de estradiol não se mostraram diferentes na

Tabela 1 - Determinações séricas de estradiol, progesterona e prolactina nos grupos analisados

\begin{tabular}{lccc}
\hline Hormônio & GCtr & GExp & Valor de $p$ \\
\hline Estradiol (pg/mL) & $119,1 \pm 12,3$ & $122,7 \pm 8,4$ & 0,418 \\
Progesterona (ng/mL) & $18,2 \pm 1,6$ & $11,3 \pm 0,9$ & $<0,001$ \\
Prolactina (ng/mL) & $45,5 \pm 5,2$ & $295,6 \pm 38,0$ & $<0,001$ \\
\hline
\end{tabular}

GCtr: grupo controle, tratado com soro fisiológico; GExp: grupo tratado com $6,7 \mu \mathrm{g} / \mathrm{g}$ de metoclopramida, por dia durante 50 dias.

Os valores representam a média $\pm E P M$ (erro padrão da média). Cada grupo era formado por 12 animais. comparação entre os grupos (GCtr $=119,1 \pm 12,3$ pg/mL e $\mathrm{GExp}=122,7 \pm 8,4 \mathrm{pg} / \mathrm{mL} ; \mathrm{p}=0,418)$. Já os de progesterona mostraram-se diminuídos no grupo hiperprolactinêmico $(\mathrm{GCtr}=18,2 \pm 1,6 \mathrm{ng} / \mathrm{mL}$ e $\mathrm{GExp}=11,3 \pm 0,9 \mathrm{ng} / \mathrm{mL}$; $\mathrm{p}<0,01$ ) (Tabela 1 ).

\section{Morfologia}

A morfologia observada nas secções transversais dos cornos uterinos mostrou-se muito parecida em todos os animais dentro do mesmo grupo de experimentação. No GCtr, foi observado endométrio bem desenvolvido, revestido internamente por epitélio cilíndrico simples e várias glândulas endometriais - algumas delas contendo figuras de mitose. O estroma endometrial mostrou-se rico em células com núcleos heterocromáticos. Este padrão é compatível com a fase de proestro em animais normais (Figura 2A).

No GExp, o endométrio está mais desenvolvido e apresenta células com núcleos volumosos ricos em eucromatina. Foi observada, ainda, maior concentração de matriz intercelular do que no GCtr. O útero estava revestido por epitélio cilíndrico simples, contendo figuras de mitose. O estroma mostra grande concentração de células com núcleos volumosos, eucromáticos, sendo ainda facilmente visíveis figuras de mitose (Figura 2B).

\section{Morfometria}

$\mathrm{Na}$ Tabela 2, estão expressos os valores morfométricos avaliados. Foi observado que as espessuras obtidas no epitélio luminal no GCtr foram menores do que no experimental (GCtr $=8,0 \pm 1,1 \mu \mathrm{m}$ e GExp=10,2 $\pm 0,8 \mu \mathrm{m}, \mathrm{p}<0,001)$. O mesmo ocorreu no endométrio (GCtr $=116,2 \pm 21,1 \times 10^{2}$ $\mu \mathrm{m}$ e $\left.\mathrm{GExp}=163,2 \pm 23,3 \times 10^{2} \mu \mathrm{m} ; \mathrm{p}<0,001\right)$. Já no
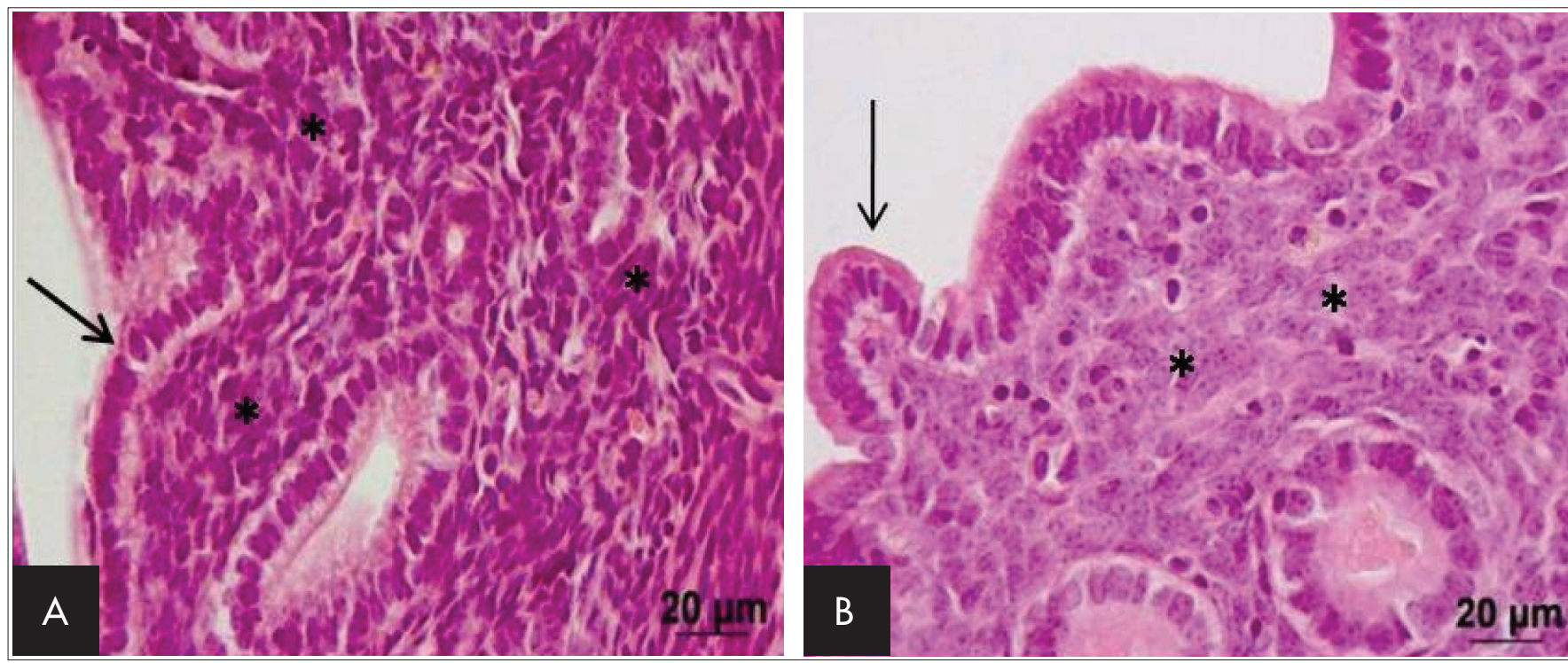

Figura 2 - Fotomicrografias que mostram regiões do endométrio de camundongos fêmas na fase de proestro. Notar, em $A$, endométrio revestido por epitélio cilíndrico simples (seta) e estroma rico em células com núcleos heterocromáticos $\left({ }^{*}\right)$ com pouca substância intercelular (GCtr). Em B, observar endométrio revestido por epitélio cilíndrico simples (seta) e estroma rico em células com núcleos volumosos (*) (GExp). Coloração H/E. 
Tabela 2 - Valores da espessura do epitélio luminal superficial, do endométrio e da camada muscular do útero de camundongos fêmeas controle ( $G(t r$, tratadas com soro fisiológico) ou tratadas com $6,7 \mu \mathrm{g} / \mathrm{g}$ de metoclopramida por dia durante 50 dias (GExp).

\begin{tabular}{lccc}
\hline Regiões do útero & $\mathrm{GCHr}$ & $\mathrm{GExp}$ & Valor de $\mathrm{p}$ \\
\hline Epitélio luminal $(\mu \mathrm{m})$ & $8,0 \pm 1,1$ & $10,2 \pm 0,8$ & $<0,001$ \\
Endométrio $\left(10^{2} \mu \mathrm{m}\right)$ & $116,2 \pm 21,1$ & $163,20 \pm 23,3$ & $<0,001$ \\
Miométrio $\left(10^{2} \mu \mathrm{m}\right)$ & $152,2 \pm 25,2$ & $140,8 \pm 18,2$ & 0,217 \\
\hline
\end{tabular}

Média \pm EPM (erro padrão da média). Cada grupo era formado por 12 animais.

miométrio, os valores se mostraram semelhantes entre si $\left(\mathrm{GCtr}=152,2 \pm 25,2 \times 10^{2} \mu \mathrm{m}\right.$ e GExp $=140,8 \pm 18,2 \times 10^{2}$ $\mu \mathrm{m} ; \mathrm{p}=0,217)$.

\section{Discussão}

A indução da hiperprolactinemia nos camundongos fêmeas foi realizada segundo protocolo preconizado, elegendo, entre as diversas substâncias antagonistas dopaminérgicas para indução de hiperprolactinemia, a metoclopramida. Nestes estudos, o fármaco foi ministrado na dose de $200 \mu \mathrm{g} / \mathrm{dia}$ (ou $6,7 \mu \mathrm{g} / \mathrm{kg}$ por dia), durante 50 dias consecutivos, e foram detectados o prolongamento do ciclo estral e a elevação dos níveis séricos de PRL. Estes dados foram confirmados no presente trabalho ${ }^{7}$.

Os resultados do presente estudo mostraram que a hiperprolactinemia induzida pela metoclopramida levou à proliferação endometrial, com aumento do número de células e de mitoses. Em consequência da proliferação celular, ocorreu aumento da espessura do epitélio luminal e endometrial. Estes resultados confirmaram os achados de outros de outros autores ${ }^{6}$, que evidenciaram adicionalmente redução no número de implantações embrionárias. Possivelmente, a adesão embrionária pode estar prejudicada devido à redução dos pinopódios ${ }^{6}$ e também a alterações presentes no endométrio, como a excessiva proliferação endometrial determinada pela metoclopramida durante a fase de proestro, verificada neste experimento. Além disso, outros trabalhos, em nosso laboratório, mostram elevação dos glicosaminoglicanos uterinos após o tratamento com metoclopramida, o que poderia contribuir também para a infertilidade nesses animais ${ }^{14}$.

O mecanismo de ação preciso da PRL no endométrio ainda não está totalmente esclarecido. São encontrados receptores de PRL na decídua, no citotrofoblasto coriônico, trofoblasto placentário e no epitélio amniótico ${ }^{15}$. Em mulheres, os receptores foram detectados, por imunoistoquímica, nos compartimentos estromal e glandular do endométrio, durante o ciclo menstrual ${ }^{16}$. Esta observação sugere possível papel da PRL no preparo do endométrio para a implantação do zigoto ${ }^{17}$. A PRL pode influenciar o processo de implantação por modificações na atividade imune endometrial ${ }^{18,19}$ e/ou pela regulação de fatores provenientes das secreções glandulares, que poderiam controlar a proliferação trofoblástica e/ou invasão do endométrio ${ }^{17}$. Além disso, foi confirmada a expressão do receptor de PRL (PRL-R) no endométrio e na decídua ${ }^{16,17}$. Métodos imunoistoquímicos e de hibridização in situ revelaram que o receptor da PRL é fortemente expresso pelo epitélio glandular e células estromais no endométrio decidualizado e pseudodecidualizado, sendo mínimo ou ausente nas fases proliferativa e secretora inicial. A expressão temporal dos PRL-R é idêntica à da PRL endometrial.

Stewart et al. ${ }^{18}$ estudaram PRL-R no endométrio de ovinos durante o ciclo estral e concluíram que a secreção de PRL endometrial estimula o desenvolvimento e a função das glândulas endometriais durante a gravidez, fato que facilitaria a implantação e a placentação do concepto. Outros relataram os efeitos da PRL em cultura de células endometriais humanas (células epiteliais e estromais), e discutiram o seu papel na implantação ${ }^{19}$. Em síntese, a PRL em baixas concentrações ( 3 a $30 \mathrm{ng} / \mathrm{mL}$ ) aumentaria a ligação e a proliferação celular.

O útero é um dos primeiros locais extra-hipofisários descritos como possível fonte de síntese e secreção de PRL. Fisiologicamente, este hormônio teria ação na diferenciação endometrial ${ }^{20}$. Em úteros não gravídicos de humanos, sua síntese foi detectada no pico das fases secretora e menstrual, coincidindo com os primeiros sinais histológicos de decidualização. Se a gravidez ocorrer, o número de células deciduais diferenciadas, bem como a síntese de PRL decidual, aumenta após a implantação, alcançando o acme entre a $20^{\mathrm{a}}$ e a $25^{\mathrm{a}}$ semanas, declinando próximo ao termo ${ }^{21}$. Possivelmente, a hiperprolactinemia poderia interferir neste mecanismo. Ademais, o processo de decidualização e as subsequentes síntese e secreção de PRL são controlados mais efetivamente pela progesterona ${ }^{22}$. É admitido que a progesterona possa influenciar a expressão gênica da PRL decidual pela indução ou regulação póstranscricional de transativadores ${ }^{23}$. Em nosso estudo, foi observada a redução dos níveis de progesterona nos animais tratados com metoclopramida, o que influenciaria a ação da PRL no endométrio, bem como poderia ter efeito direto nos dados histomorfométricos analisados. Portanto, nossos resultados sugerem que a hiperprolactinemia induzida pela metoclopramida leva, fundamentalmente, à proliferação endometrial, que decorre possivelmente da interferência na função ovariana, principalmente na produção da progesterona. 


\section{Referências}

1. Yavasoglu I, Kucuk M, Coskun A, Guney E, Kadikoylu G, Bolaman Z. Polycystic ovary syndrome and prolactinoma association. Intern Med. 2009;48(8):611-3.

2. Sultana A, Nadir S. Pituitary gonadotropic hormones in women with oligo/amenorrhoea. J Ayub Med Coll Abbottabad. 2008;20(3):62-5.

3. Molitch ME. Prolactin in human reproduction. In: Strauss JF, Barbieri RL, editors. Yen, Jaffe's reproductive endocrinology. 5th ed. Philadelphia: Elsevier Saunders; 2004. p. 93-124.

4. Hnasko TS, Hnasko RM, Sotak BN, Kapur RP, Palmiter RD. Genetic disruption of dopamine production results in pituitary adenomas and severe prolactinemia. Neuroendocrinology. 2007;86(1):48-57.

5. Ugryumov MV, Mel'nikova VI, Ershov PV, Balan IS, Kalas A. Nondopaminergic neurons expressing dopamine synthesis enzymes: differentiation and functional significance. Neurosci Behav Physiol. 2002;32(3):299-307.

6. Panzan MQ, Soares JM Jr, da Motta EL, Haapalainen EF, Simões M, Baptista HA, et al. Metoclopramide-induced hyperprolactinaemia caused marked decline in pinopodes and pregnancy rates in mice. Hum Reprod. 2006;21(10):2514-20.

7. Rossi AG, Soares JM Jr, Motta EL, Simões M, Oliveira-Filho RM, Rodrigues de Lima $G$, et al. Metoclopramide-induced hyperprolactinemia affects mouse endometrial morphology. Gynecol Obstet Invest. 2002;54(4): 185-90.

8. Verna C, Soares Júnior JM, Martins FW, Teixeira RC, Mosquette $R$, Simões RS, et al. Efeito da hiperprolactinemia induzida pela metoclopramida na córnea de camundongas. Arq Bras Oftalmol. 2006;69(5):645-9.

9. Suginami H, Hamada K, Yano K, Kuroda G, Matsuura S. Ovulation indution with bromocriptine in normoprolactinemic anovulatory women. J Clin Endocrinol Metab. 1986;62(5):899-903.

10. Seki K, Kato K. Responses of growth hormone to metoclopramide in normal women and amenorrheic women with or without hyperprolactinemia. Endocrinol Jpn. 1986;33(5):721-5.

11. Rossi AG, Teixeira Gomes RC, de Jesus Simões M, Dos Santos Simões R, Oliveira PB, Soares JM Jr, et al. Effects of metoclopramideinduced hyperprolactinemia on the prolactin receptor of murine endometrium. Fertil Steril. In press 2009.

12. Verna C, Martins FW, Mosquette R, Simões RS, Simões M, Soares Junior JM, et al. Efeito da hiperprolactinemia induzida pela metoclopramida na glândula lacrimal: estudo experimental. Rev Bras Ginecol Obstet. 2005;27(9):524-8.

13. Koike K, Miyake A, Aono T, Sakumoto T, Ohmichi M, Yamaguchi M, et al. Effect of prolactin on the secretion of hypotalamic $\mathrm{GnRH}$ and pituitary gonadotropins. Horm Res. 1991;35 Suppl 1:5-12.

14. Gomes RC, Simões RS, Soares Jr JM, Nader HB, Simões M, Baracat EC. [Profile of sulphated glycosaminoglycans content in the murine uterus during the different phases of the estrous cycle]. Rev Assoc Med Bras. 2007;53(3):261-6. Portuguese.

15. Maaskant RA, Bogic LV, Gliger S, Kelly PA, Bryant-Greenwood GD. The human prolactin receptor in the fetal membranes, decidua, and placenta. J Clin Endcocrinol Metab. 1996;81 (1):396-405.

16. Jones RL, Critchley HO, Brooks J, Jabbour HN, McNeilly AS. Localization and temporal expression of prolactin receptor in human endometrium. J Clin Endocrinol Metab. 1998;83(1):258-62.

17. Jabbour HN, Critchley HO, Boddy SC. Expression of funcional prolactin receptors in nonpregnant human endometrium: janus kinase-2, signal transducer and activator of transcription-1 (STAT1), and STAT5 proteins are phosphorylated after stimulation with prolactin. J Clin Endocrinol Metab. 1998;83(7):2545-53.

18. Stewart MD, Johnson GA, Gray CA, Burghardt RC, Schuler $L A$, Joyce $M M$, et al. Prolactin receptor and uterine milk protein expression in the ovine endometrium during the estrous cycle and pregnancy. Biol Reprod. 2000;62(6):1779-89.

19. Negami Al, Tominaga T. Effects of prolactin on cultured human endometrial cells. Horm Res. 1991;35 Suppl 1:50-7.

20. Golander A, Hurley T, Barrett J, Hizi A, Handwerger S. Prolactin synthesis by human chorion-decidual tissue: a possible source of prolactin in the amniotic fluid. Science. 1978;202(4365):311-3.

21. Wu WX, Brooks J, Glasier AF, McNeilly AS. The relationship between decidualization and prolactin mRNA and production at different stages of human pregnancy. J Mol Endocrinol. $1995 ; 14(2): 255-61$.

22. Maslar IA, Ansbacher R. Effects of progesterone on decidual prolactin production by organ cultures of human endometrium. Endocrinology. 1986;118(5):2102-8.

23. Gellersen B, Kempf R, Telgmann R, DiMattia GE. Nonpituitary human prolactin gene transcription is independent of Pit- 1 and differencially controlled in lymphocytes and in endometrial stroma. Mol Endocrinol. 1994;8(3):356-73. 